\title{
NEGOCIACIÓN COLECTIVA Y CONTROL SINDICAL. ASPECTOS LABORALES Y ECONÓMICOS*
}

\author{
NiKo IRIARTE \\ Economista. Gabinete Económico y de Negociación Colectiva \\ de Euskal Langileen Alkartasuna (ELA)
}

DOI: $10.1387 /$ lan-harremanak.17501

Recibido el 30 de septiembre de 2016

Aceptado el 15 de octubre de 2016

\section{ABSTRACT}

Resumen: En esta ponencia se informa sobre la actividad diaria del Gabinete de Negociación Colectiva del sindicato ELA: en los despidos colectivos sufridos, en los cierres de empresas, en los procesos concursales... Explicaremos cuál es la documentación que exigimos y la estrategia que pone en práctica nuestro sindicato., de cara a evitar esta dificiles situaciones.

Queremos destacar el comportamiento de los grupos de empresas, las valoraciones (juridicas) y no económicas que los jueces hacen de despidos por causas económicas y queremos subrayar, sobre todo, que las multinacionales hacen en casi todos los casos lo que quieren con el beneplácito del poder institucional.

* Ponencia con la que participó en la Mesa redonda: Perspectiva profesional de los fundamentos económico-jurídicos para abordar la negociación colectiva y el control sindical económico, en el II Encuentro de Profesionales del Asesoramiento Laboral y Social, celebrado en la Facultad de Relaciones Laborales y Trabajo Social (UPV/EHU-Leioa) el día 30 de septiembre de 2016. 
Para finalizar, se expone el Modelo Social del Sindicato ELA, que es el más importante de sus tres ejes estratégicos, junto con el trabajo sindical, sin olvidarnos del eje politico.

Laburpena: Ponentzia honetan ELA sindikatuko Negoziazio Kolektiboko Gabinetearen eguneroko lanen berri ematen da: izaten ditugun kaleratze kolektiboetan, enpresa itxieretan, hartzekodunen prosezuetan... eskatzen dugun dokumentazioa eta egoera zail hauek sahieste aldera Sindikatuak aurrera eramaten duen estrategia eta lan koordinatua azaltzen dira.

Aipatzekoa da enpresa taldeen jokamoldea kasu hauetan, epaileek egiten duten balorazio juridiko eta ez ekonomikoa iraizpenaren arrazoia ekonomikoa denean eta batez ere azpimarratu nahi dugu Multinazionalek nabi dutena egiten dutela botere instituzionalen oniritziarekin kasu ia gehienetan.

Bukatzeko ELA sindikatuaren Gizarte Eredua azaltzen da sindikatuak dituen 3 ardatz estratejikoetatik garrantzitsuena lan sindikalarekin batera eta ardatz politikoa ahaztu gabe. 


\section{SUMARIO}

Sumario: 1. Introducción - Contextualización. 2. Perspectiva profesional de los fundamentos económico-jurídicos para abordar la negociación colectiva y el control sindical económico. 2.1. Información económica, productiva, de procesos... 2.2. Empresas según su composición societaria: empresas individuales / grupos de empresas. 2.3. Precios de transferencia. 2.4. Reestructuraciones empresariales. 2.5. Búsqueda de soluciones óptimas buscando la viabilidad futura de las empresas. 3. Modelo de sociedad que propugna ELA. 3.1. Política fiscal. 3.2. Política económica y presupuestaria. 3.3. Sistema financiero.. 3.4. Política de empleo y formación propia. 3.5. Negociación colectiva y diálogo social. 3.6. Política industrial. 3.7. Medidas y políticas necesarias a implantar por el Gobierno Vasco y las Diputaciones Forales vascas. 3.8. Prestaciones sociales y establecimiento legal de derechos sociales. 3.9. Carta de Derechos Sociales de Euskal Herria. 4. Conclusiones finales.

\section{Introducción - Contextualización}

El objetivo fundamental de esta ponencia es explicar la experiencia práctica que, desde el sindicato ELA y más concretamente desde el Gabinete de Negociación Colectiva de ELA, desarrollamos en los temas que nos toca gestionar en el día a día, relacionados con la Negociación Colectiva, expedientes de Regulación de Empleo de todo tipo, reestructuraciones empresariales que nos plantean, numerosos concursos que hemos tenido en el marco de esta larga crisis cuyo fin de momento no se vislumbra y, en los peores casos, los cierres de empresas que se han sucedido de empresas del País y también de empresas multinacionales.

El sindicato ELA, EUSKAL LANGILEEN ALKARTASUNA, por dar dos pinceladas de presentación de quienes somos y a que nos dedicamos, es un sindicato de clase, abertzale, independiente económica y políticamente, con una representación en la Comunidad Autónoma del País Vasco del 40,17\% en la Comunidad Foral de Navarra de un 22,49\% en máximos históricos (agosto de 2016).

ELA se organiza en 3 federaciones, Industria y Construcción, Servicios Públicos (Gizalan) y Zerbitzuak, y 12 Estructuras Interprofesionales, en 12 Co- 
marcas que abarcan la totalidad de Hego Euskal Herria. Además, está presente en Iparralde con la Fundación Manu Robles-Arangiz.

El Gabinete de Negociación Colectiva en ELA es un instrumento más para la acción sindical, porque el objetivo fundamental de ELA es organizar a los trabajadores, dar una respuesta a sus intereses legítimos, tratando de mejorar en todo momento la correlación de fuerzas para obtener o maximizar su presencia de «intorlocutoriedad» en las mesas de negociación, de cara a conseguir los objetivos propuestos. Así, todos y cada uno de los temas se abordan desde este prisma.

Afrontamos cada uno de los procesos de manera integral y coordinada entre Confederación, federación, comarcas, centros de trabajo, secciones sindicales y gabinetes (negociación colectiva, servicios jurídicos...) ${ }^{2}$.

\section{Perspectiva profesional de los fundamentos económico-jurídicos para abordar la negociación colectiva y el control sindical económico}

En este segundo punto, trataré de responder a las preguntas que se realizan por parte de los organizadores del encuentro en esta mesa de una forma totalmente práctica y teórica profesional, puesto que mi acción en el campo de la empresa y de los sectores es ayudar, como militante ELA y miembro del Gabinete de Negociación Colectiva, al desarrollo de las decisiones de los órganos del Sindicato.

Quiero destacar, por otra parte, que siendo el único economista de la mesa sería una osadía imperdonable por mi parte tratar de abordar debates jurídicos que se han planteado o se vayan a plantear por mis compańeros de mesa, todos ellos prestigiosos juristas de asesorías laborales y del resto de sindicatos presentes.

Por lo que, sin más precisiones, abordaré los temas concretos a desarrollar en la mesa desde un punto de vista estrictamente económico.

La primera idea principal que quiero trasladar es la referente al modelo de relación que ELA busca en todas las empresas y procesos que nos toca gestionar que, como somos el primer sindicato de Euskal Herria, son más de los que quisiéramos. La primera conclusión que extraemos es que, por desgracia para todos nosotros, los ejemplos de buenas practicas o que se ajustan al modelo de relación que ELA busca en las empresas son la excepción (sobran dedos de una

2 Para obtener más información véase la página web del sindicato: www.ela.eus. 
mano para contarlos). De hecho, en la mayoría de empresas el modelo existente es muy distinto, por no decir diametralmente opuesto al nuestro.

El modelo de relación que impulsamos desde el sindicato ELA se basa en la confianza mutua y la transparencia entre el empresario y la parte social, para tratar de buscar coincidencias de intereses de desarrollo del proyecto empresarial en todas y cada una de las empresas en las que tenemos afiliados y representantes de los trabajadores, antes de confrontar por la distribución de los resultados .

Dicho de otra manera, ello implica para ambas partes mantener relaciones de confianza, basadas en el reconocimiento mutuo, transparencia, máxima honestidad y con todas las cartas encima de la mesa, por un lado, para tratar de llegar a aquellos acuerdos, sin renuncias ideológicas, que optimicen los intereses comunes de ambas partes; acuerdos que se podrían concretar en el convenio colectivo y, por otro lado, para garantizar la buena marcha de la empresa desde muchos puntos de vista, económico, laboral, participación, cooperación en la búsqueda de los objetivos marcados entre ambas partes.

Las conclusiones que obtenemos de las experiencias empíricas son que, desgraciadamente, existen pocos casos prácticos y reales en los que se desarrolla este tipo de relación en las empresas, aunque algunos existen.

Cuando anteriormente me refería «a con todas las cartas encima de la mesa» trataba de dar a entender que eso implica la transparencia total entre ambas partes, por ejemplo: que la parte social pueda tener acceso toda la información necesaria, que para nada se circunscribe a la estrictamente legal, sino que, a nuestro entender, implica el acceso a toda la información de que dispone, de forma, exclusiva, la empresa. De esta forma, mediante la utilización discreta de la misma por la parte social, se puede profundizar en esa relación de confianza por la que abogamos y apostamos desde el sindicato ELA.

Siempre ofrecemos esta oportunidad a todos los empresarios en las empresas en las que participamos y, por desgracia, en muy pocas ocasiones obtenemos una contestación afirmativa por parte de ellos, por lo que, en nuestro caso, no hacemos más que adaptarnos al tipo de relación real y efectiva que se nos ofrece por parte del empresariado vasco. Es decir, la formal no implica la real.

Si no obtenemos respuesta positiva al ofrecimiento, nuestra actitud y compromiso va desarrollándose en función de este condicionante y difícilmente podrá haber complicidades de empatía en cuanto a los objetivos e intereses entre ambos interlocutores. O sea, si la otra parte no apuesta ni ofrece lo que desde ELA razonablemente se promueve, la relación de confianza e interlocutoriedad queda en cuestión .

En ELA entendemos que la dirección de la empresa o los propios propietarios tienen que ser los que promuevan y animen este tipo de relaciones, ya que 
un mejor conocimiento de la situación concreta de la empresa y de los objetivos hacia donde se dirigen deben ser trasladados a los actores de la misma (incluidos los trabajadores), con el objeto de que visualicen todos ellos cuáles son los objetivos a cumplir y quienes son los responsables de gestionar todos los recursos materiales, humanos... de la empresa para la consecución de dichos objetivos. En esta labor, nuestra función consiste en trabajar, colaborar, cooperar en la obtención de dichos objetivos comunes (laborales-sociales incluidos), en base a esa relación de reconocida confianza mutua preestablecida y a los acuerdos y consensos obtenidos entre ambas partes en un proceso que lo calificamos como participativo.

Desarrollada esta primera idea principal, que es la clave de toda nuestra función en todos los procesos que nos toca gestionar, de muy distintos tipos en función de la problemática especifica que se nos presente en cada empresa concreta, expondré, a continuación, lo que, desde un punto de vista práctico, nos solemos encontrar en los procesos concretos en empresas.

\subsection{Información económica, productiva, de procesos...}

En los expedientes concretos de despidos colectivos, cierres de empresa, concursos... normalmente nos encontramos con los Informes Técnicos y Memorias elaborados por «bufetes» muy bien pagados, muy prestigiosos que, además, ofrecen un servicio total o integral a la empresa demandante. Habitualmente, esa acción coordinada suele estar acompañada por los peritos encargados de tratar de probar en los juicios la existencia de la causa que la empresa alega para solicitar los despidos, cierres, reestructuraciones...

Nuestra amplia experiencia nos demuestra que, normalmente, los autores de estos informes técnicos no efectúan el trabajo siguiendo un proceso lógico de trabajo, que consistiría, en primer lugar, en un análisis de la información pertinente para determinar si existe la causa o causas motivadoras del expediente, sino que realizan el proceso de forma inversa, es decir, en función de la conclusión prefijada buscan los argumentos y pruebas que les lleven a justificar dicho objetivo prefijado o determinado. Esto es, ellos analizan toda la información que la empresa en estos casos sí pone a su disposición, además con el máximo de tiempo posible para que puedan elaborar esos informes técnicos que, paradójicamente siempre llegan a la misma conclusión, que es la que busca el empresario que les contrata.

En este caso, desde ELA siempre solicitamos, al menos, la misma información que los autores de estos informes técnicos han podido analizar con todo el tiempo del mundo, para que la parte social — comité de empresa, delegado de personal o RLT - pueda buscar contradicciones; información que se nos niega con el argumento de que los «expertos» independientes contratados ya la han analizado y han llegado a las conclusiones expuestas en el informe técnico. De 
esta forma, las empresas pretenden investirles del carácter de notarios imparciales de los bufetes contratados el papel de notarios imparciales de los contratados bufetes, sin que se permita a la parte social y a la autoridad laboral contrastar dicha información..

Como ejemplo citaré la documentación que normalmente no se aporta: planes operativos, planes estratégicos, precios de transferencia en las operaciones intragrupo, contabilidad analítica para poder determinar costes unitarios por producto o familias de productos, pecios de venta unitarios o al menos medios por productos o familias de productos, márgenes... No es una lista exhaustiva, simplemente trato de exponer lo mínimo que se solicita como información complementaría en todos estos procesos largos, duros y difíciles en los periodos de consultas muy tasados en la normativa legal.

Se hace especial énfasis a la hora de solicitar y analizar las Cuentas Anuales Individuales de la empresa y, sobretodo. las cuentas Anuales Consolidadas del conjunto del Grupo, si la empresa comunicante del expediente pertenece a un grupo de empresas. Para demostrar que las operaciones entre vinculantes tanto financieras, comerciales o de servicios son utilizadas para fines que justifican las causas motivo de los Expedientes. Añado, que esta dificultad se agrava, si el grupo tiene una matriz fuera del Estado.

No me alargaré más con esta cuestión, puesto que posteriormente lo trataré con mayor extensión, ya que es una cuestión de máxima preocupación, que merece ser analizada en profundidad, por las trascendentales consecuencias que, para nuestros representados, los trabajadores, tiene esta cuestión capital y que está siendo aprovechada por las empresas con la máxima impunidad, con la máxima aquiescencia de los Tribunales y Juzgados, de todos los ámbitos geográficos tanto locales, autonómicos, estatales como internacionales.

Otro de los puntos muy a tener en cuenta en estos procesos es la búsqueda de aliados dentro de la empresa (en sus dos vertientes sindicales como profesionales de la empresa), a la hora de poder valorar si la información suministrada por la propia empresa es fidedigna o no (creíble y constatable) y hacer el correspondiente chequeo de dicha información para poder valorar la razonabilidad y verosimilitud de la misma. Es un proceso difícil y complicado, pero que, de poder realizarlo en las mejores condiciones, aporta un valor muy importante a nuestra función de dejar sin efecto lo solicitado por la empresa y hacer propuestas alternativas. En casos concretos de Multinacionales, hemos podido constatar fehacientemente e incluso con documentación interna que la decisión de cierre se había tomado por parte de la multinacional varios ańos atrás, con informes y planes de cierre perfectamente elaborados, debatidos en los órganos societarios correspondientes y ejecutados a largo plazo dentro de un plan estratégico. Por lo que a veces, el ERE de extinción 
tan sólo era la parte final, pero necesaria formalmente considerada del plan de cierre prefijado.

En casos extremos, y por el tiempo que requiere y los recursos finitos de los que disponemos, desde el Gabinete de Negociación Colectiva de ELA se solicitan las cuentas de Mayores de la empresa, con el fin de realizar una mini-auditoría de la empresa para poder extraer las correspondientes conclusiones que nos ayuden en el objetivo final de evitar los despidos o cierres de las empresas. Sabemos que nos vamos a tener que enfrentar, con demandas judiciales elaboradas por nosotros, a procedimientos y leyes elaboradas contrarias a los intereses de los trabajadores, a autoridades laborales que no se quieren enfrentar a sus superiores políticos y a tribunales que se amparan y alinean en las corrientes políticas del momento en lugar de explorar las escasas vías que dejan los legisladores.

Me voy a parar en este momento para explicar otra idea fundamental que en ELA tenemos con respecto a estos procesos y es que, tal y como he indicado en la introducción, el gabinete y demás recursos de la confederación jugamos un papel totalmente secundario, de última alternativa, sin restarle importancia, puesto que, si nos toca actuar es porque en la lucha sindical no se ha podido conseguir el objetivo principal de evitar los despidos o cierres de empresa, pero cuando llega este momento, es en este ámbito donde se hace el máximo hincapié, ya que, a pesar de que es en la lucha sindical donde se obtienen los mejores resultados, porque es el momento crucial del conflicto donde se constata la verdadera relación de fuerzas existente entre las dos partes y de donde puede salir una solución que desatasque el devenir futuro del conflicto, por lo que se constata claramente el papel y función totalmente secundario del Gabinete y los servicios jurídicos que entra en acción irremediablemente cuando por desgracia el objetivo fundamental no se haya obtenido en la primera y decisiva fase de la lucha sindical.

\subsection{Empresas según su composición societaria: empresas individuales /grupos de empresas}

A la hora de valorar los procesos que se están describiendo, nos entramos con dos tipos de empresas: por una parte, las empresa individuales que no forman parte de ningún grupo empresarial y, por otra parte, las empresas individuales que forman parte de un grupo empresarial.

El primer caso, en apariencia, es el más simple. No por ello más sencillo. Pero normalmente, suelen ser procesos de menor complejidad, debido a que toda la actividad económica y el patrimonio se concentra en una sola empresa; mientras que, en el segundo tipo de empresas, al pertenecer a un grupo empresarial, a la hora de abordar un proceso de estas características, el trabajo a desarrollar, material a examinar e informe a realizar no tiene nada que ver con el primer supuesto. 
En el segundo caso, lo primero que debemos valorar es la estructura del grupo, subgrupos, divisiones del Grupo que, a su vez, pueden depender todas de una empresa matriz o holding, que es donde normalmente reside el máximo poder de decisión, pero también, nos podemos encontrar con casos de grupos empresariales desconexos o que no tienen un ámbito común o final de consolidación y que, sin embargo, actúan como una única unidad de acción y decisión, sin que por ello pueda establecerse una responsabilidad unitaria del conjunto del grupo que se divide en los ámbitos desconexos en los que este compuesto el grupo.

En estos casos de Grupos empresariales, cuando la causa es económica, siempre se solicitan las cuentas Consolidadas del Conjunto del grupo o subgrupo ... para poder realizar una valoración exclusivamente económica del Grupo, previa a cualquier otra consideración de tipo jurídico, remarco esta idea, puesto que, siempre en estos casos, desde el ámbito jurídico se establece una premisa "falsa" previa y es que su única intención es ver o demostrar la patología laboral, de tener que probar o establecer la existencia de grupo laboral patológico en el ámbito del grupo empresarial con los elementos adicionales que este «constructo» interesado jurídico establece en la doctrina jurisprudencial, dificultando totalmente la consideración exclusiva en términos económicos del grupo y diluyendo totalmente la consideración de grupo empresarial a la hora de realizar la valoración económica del grupo empresarial y establecer si existe la causa económica o no planteada por la empresa normalmente filial del grupo empresarial. Esto se debe principalmente, y salvo excepciones, a que los tribunales de lo social y los abogados laboralistas saben muy poco de derecho mercantil, y sus acciones no van a relacionar ambas cosas, cuales son que las operaciones vinculadas entre empresas del grupo producto de sus decisiones afectan al empleo, sus condiciones y ámbitos de desarrollo empresarial (patrimonial, comercial, financiera y servicios).

En este sentido, el Gabinete de Negociación Colectiva ha tratado de aclarar la cuestión contactando con el ICAC (Instituto de Contabilidad y Auditoría de Cuentas ), para que determinara el ámbito de valoración del grupo, en su conjunto o la empresa individual filial que normalmente insta el expediente. Desgraciadamente, no se ha obtenido ningún tipo de respuesta al respecto. Actualmente, estamos esperando la respuesta del Tribunal Supremo en un caso de estas características que, ademas, reúne otras muy especificas: el de Eusko Irratia, de despido colectivo por causas económicas que, planteada la correspondiente alegación, esperamos valoren y determinen la cuestión para saber a qué atenernos en estas situaciones muy comunes y que, por ahora, por desgracia, todos los fallos vienen determinados por la posición previa totalmente jurídica ya descrita de tener que establecer previamente la consideración de Grupo Laboral Patológico sin previamente realizar la valoración exclusivamente económica del Grupo empresarial patológico o no. 
Esta cuestión es vital o fundamental para nosotros, puesto que, en función de lo que el Tribunal Supremo establezca definitivamente en esta materia, nos podemos encontrar con que no existe terreno de juego para poder desarrollar el partido, por utilizar términos futbolísticos; ya que si se decide la previa constatación de la existencia de grupo laboral patológico o no, deja poco margen para tener que realizar la valoración económica del grupo en función de las cuentas Anuales Consolidadas del grupo empresarial por tener como referencia única de valoración económica las Cuentas Individuales de la filial sin considerar en absoluto, lo previo, lo mercantil, cual es ella base de la decisión del ERE, que es la valoración económica de las cuentas Consolidadas a la hora de valorar la existencia o no de causa económica en un expediente de despido colectivo instado por una empresa filial que pertenece cuando consolida sus Cuentas con el resto de empresas dominadas y dominante para elaborar las Cuentas Anuales Consolidadas.

Si no se tiene en cuenta nuestra petición, mucho nos tememos que, en despidos colectivos de este tipo, sea imposible determinar la relación de causalidad previa, porque no se entra a valorar el conjunto del grupo y que se establezca la causa económica de la filial sin realizar la valoración económica del conjunto del grupo. Hemos padecido en carne propia estas situaciones con ejemplos concretos del día a día en Tubos Reunidos, Koyo, Laminaciones Arregui (CELSA ATLANTIC) ...

\subsection{Precios de transferencia}

Otro tema ligado a la causa económica es el de los precios de transferencia, ya que en absoluto se entrega la información contable solicitada y demandada por la parte social en este tipo de procesos para constatar que no son las operaciones vinculadas a estos precios las causantes de la medida.

Las empresas normalmente realizan afirmaciones de tipo genérico en el sentido de decir que se realizan a precios de mercado sin dar ningún otro tipo de explicación o mayor detalle en las operaciones realizadas entre las distintas empresas de un mismo grupo como son el precio sectorial, ... y no pasa nada.

La ley obliga a determinar estos precios de transferencia por operaciones intragrupo, cuando no existe un precio de mercado referencia de operaciones o de aproximaciones lo más parecidas o más equivalentes posibles que se dan en el mercado. En los procesos que analizamos sucede que en ningún momento entran a describir, aportar documentación alguna de este tipo ni tampoco en los periodos de consultas entregan ninguna documentación que hagan referencia a este tipo de operaciones y si además a esto le unimos, que sin el acceso a las cuentas de mayores ni a las operaciones intragrupo concretas, en las prácticas que se dan son imposibles de detectar operaciones de este tipo que sean fraudulentas o que no cumplan con la legalidad. 


\subsection{Reestructuraciones empresariales}

En estos casos desde el Gabinete queremos destacar que el papel lo aguanta todo y realizamos una valoración integral de las propuestas que realizan las empresas para poder determinar con la mayor precisión posible la razonabilidad de las medidas a implementar y sobre todo, la verosimilitud y realización efectiva de la propuesta analizando de forma integral la propuesta y el plan de empresa o de viabilidad que se plantea en todos y cada uno de los elementos que lo componen, como pueden ser el plan industrial, financiero, de recursos humanos, promotores del proyecto, liderazgos existentes en el proyecto...

Además de realizar un seguimiento permanente en el tiempo del grado de ejecución y de las desviaciones producidas y las acciones correctoras propuestas por la dirección de la empresa ante tales desviaciones. Porque en estas propuestas es frecuente encontramos con la búsqueda de beneficio con ajustes o sustituciones de personal para buscar un abaratamiento de las condiciones laborales, puesta en marcha de medidas de flexibilidad, subcontrataciones,.... que muy poco tienen que ver con problemas estructurales de empresa en el negocio sectorial donde está ubicada, ejemplo.- Sector financiero, construcción, energía o comunicaciones por citar algunos.

\subsection{Búsqueda de soluciones óptimas buscando la viabilidad futura de las empresas}

Cuando hay problemas reales de liderazgo, relevo generacional, solvencia, financiación, pérdida de mercado, etc., en definitiva estructurales, nos encontramos con verdaderos problemas de abandono empresarial y liderazgo funcional en las empresas.

Y es cuando una parte muy importante de nuestro tiempo, la dedicamos a la búsqueda muchas veces infructuosa de inversores de todo tipo industriales, financieros...para las empresas en situaciones complicadas. En esta labor nos encontramos solos, ya que las instituciones ejercen un papel puramente de imagen.

Así pues, como el contacto directo con ellos normalmente es imposible, porque no es nuestro espacio natural de trabajo, en nuestro caso, contactamos con intermediarios de la máxima confianza posible que están en el mercado para poder colocar estas empresas con sus necesidades y se busque confluencia de intereses donde los inversores finales a los que pueda interesar estos temas se aproximen a las empresas.

Con gran pesar, tengo que comentar que apenas existen este tipo de inversores vocacionales a los que calificamos de «industriales» porque lo que abundan son los financieros, llamados «buitres» por su nivel de inversión especulativa y que nos cuesta dios y ayuda, contactar con alguno y que además lleguen a buen 
puerto este tipo de operaciones. Lo normal son fondos buitres, con nula capacidad inversora sin querer arriesgar en absoluto y esperando la máxima ganancia en el menor tiempo posible. Es el pan nuestro de cada día en este sentido.

Aprovecho la ocasión para tirar de las orejas a las distintas Instituciones vascas como son Gobierno Vasco, Diputaciones Forales, empresas públicas, entidades financieras con arraigo,... por la nula eficacia que nos demuestran en esta fundamental función a la hora de buscar alternativas y salvaguardar la viabilidad futura de las empresas vascas, puesto que, por desgracia, en muy contadas ocasiones logran atraer inversores dispuestos a apostar, invertir en las empresas en este tipo en situación de viabilidad o que busquen complicidades sectoriales o que convenzan para financiar operaciones de negocio posibilitando la viabilidad futura de estas empresas.

Se dan situaciones paradójicas como que ha habido ocasiones en que a inversores interesados contactados por nosotros, las instituciones les han jugado más a la contra que a favor y que en vez de ayudar y empujar, han puesto todo tipo de impedimento para que el proyecto salga y finalmente se deslocalicen las empresas o no evitar su cierre. En estos casos, por ejemplo, son referencia las actuaciones de la Seguridad Social y FOGASA que derivan sus deudas imposibilitando los proyectos.

\section{Las empresas de lo social (Coop, SALes,...) Última opción}

En situaciones de este tipo el plantearse una Sociedad de la economía de lo social es de lo más tentador, común pero no lógico y aunque es una opción que solemos valorar pero siempre, como un instrumento temporal finito porque no es una idea empresarial que nace con un mínimo de vocación sino más como un remedio a una situación de pérdida del empleo, mientras dure la llegada de un inversor líder natural y no con garantía de permanencia a futuro a mantener.

Por este motivo destaco que no es lo mismo una sociedad laboral que una cooperativa, la primera difícilmente nace como necesidad vocacional del emprendedor y en cambio la cooperativa, sí. Por consiguiente me centraré en estos casos que son los que en años de crisis se dan como oportunidad para mantener unos proyectos lanzados con otras formulaciones societarias y que conllevan el mantenimiento de los puestos de trabajo y sus condiciones.

En los periodos transitorios de búsqueda de inversores y con el objetivo fundamental de mantener el empleo y las condiciones laborales del conjunto de la plantilla, el planteamiento general que desde ELA realizamos en estas ocasiones de emergencia es la de que sea una opción personal voluntaria de todos los trabajadores de la empresa que deciden continuar y en estos casos muy concretos, previa negociación de todos los trabajadores se ha llegado a un consenso entre los que optan por irse de la empresa con una indemnización superior a la legal 
financiada bien por los que optan por quedarse en la SAL o bien por el empresario que se va.

En ocasiones ese periodo transitorio se alarga mucho más de lo previsto y se da todo tipo de situaciones, desde empresas que no acaban de morir pero viven una agonía permanente hasta que finalmente terminan en un concurso y con la correspondiente liquidación, hasta también las que tras remontar la situación adversa se sitúan en una situación muy buena y no quieren ni admiten que nadie ajeno vuelva a liderar el proyecto.

Un ejemplo muy claro de esta última situación se vivió en la empresa PAPRESA de Rentería que tras vivir una situación económica muy complicada en los noventa del siglo anterior después remontó de una manera espectacular la situación y el problema posteriormente fue cómo vender las participaciones de los socios trabajadores de la SAL a un inversor interesado cuando quiso comprar la empresa a los socios trabajadores.

Estas situaciones suelen ser complicadas de gestionar en todos sus aspectos para nuestro sindicato puesto que con los intereses de los trabajadores se mezclan los intereses de empresa de la que son propietarios. Y reconociendo que somos muy buenos en nuestro trabajo diario sindical pero la propia gestión de la empresa y la fijación de objetivos y el desempeñar el rol de empresario en la captación de pedidos, gestión interna de los distintos departamentos... junto a la convivencia de distintos tipos de trabajadores se convierte en una situación muy compleja. Es entonces cuando en estas ocasiones se da unas situaciones complicadas entre los socios trabajadores con trabajadores ajenos en los que hay unos intereses muy contrapuestos porque los socios trabajadores están más pendientes del reparto de dividendos y/o mínimización de pérdidas mientras los trabajadores ajenos están más pendientes de la $\mathrm{Ne}$ gociación Colectiva con el objetivo de mejorar sustancialmente sus condiciones laborales lo que trae como consecuencia los enfrentamientos y búsqueda de objetivos coincidentes entre los distintos tipos de trabajadores que cohabitan en la SAL.

En otras ocasiones y ante un posible planteamiento de SAL, el riesgo y la incertidumbre que rodea al nuevo proyecto empresarial sin visos a corto y medio plazo de que pueda aparecer un inversor/impulsor del nuevo proyecto y sabiendo que, en absoluto, en condiciones normales, las mismas aconsejan apostar por la nueva SAL por las nefastas consecuencias que puedan surgir si el proyecto no cuaja, surge el problema de la incertidumbre de reconocer los problemas o la tabla de salvación al empleo, único activo de los trabajadores. Y es entonces cuando se convierte en un quebradero de cabeza para todos los socios trabajadores que puedan optar por este último clavo ardiendo que finalmente acaba quemando a los trabajadores con un segundo proceso concursal o un primero con liquidación directa. 


\section{Modelo de sociedad que propugna ELA}

Dentro de los 3 ámbitos estratégicos de actuación en los que trabaja ELA, el modelo de sociedad es de capital importancia para el sindicato y complementa el propio trabajo propiamente sindical a la hora de hacer realidad un reparto justo de la riqueza en la permanente búsqueda de la justicia social.

En este sentido y desde la perspectiva de contra-poder que guía en todo momento al sindicato ELA realizamos constantes propuestas a la sociedad y a las distintas instituciones de Euskal Herria para que se lleven a cabo las políticas sociales que en nuestra opinión, los gestores públicos deberían implementar con respecto a todo tipo de temas que influyen en las necesidades de los trabajadores y de las personas más vulnerables de la sociedad.

En este sentido queremos destacar las propuestas que ELA realiza con respecto a:

- Política fiscal en la CAPV-CFN-Juntas Generales de Araba, Gipuzkoa y Bizkaia.

- Política económica

- Política de empleo

- Política industriales

— Carta de Derechos Sociales de Euskal Herria

Expondré seguidamente un resumen de las propuestas que ELA ha realizado a los partidos políticos vascos que han participado en las Elecciones Autonómicas al Parlamento Vasco el pasado domingo 25 de Septiembre con respecto a:

\subsection{Política fiscal}

- La participación en el Consejo Vasco de Finanzas y en el Órgano de Coordinación Tributaria debe utilizarse para aprobar medidas fiscales justas y progresivas, que coloquen la presión fiscal vasca en la media europea:

- Dar marcha atrás en las rebajas de impuestos aprobadas en años anteriores a las rentas altas y capital ( IRPF, Impuesto sobre Sociedades e impuesto sobre Patrimonio).

- Aprobar los cambios fiscales recogidos en las propuestas de ELA sobre esta materia.

- Exigir que se luche contra el fraude fiscal, inspeccionando anualmente al menos al 25\% de las rentas no salariales.

- Asimismo, se deben dar todos los cambios necesarios para que los impuestos (tanto los concertados como los no concertados) se decidan en el Parlamento Vasco. 


\subsection{Política económica y presupuestaria}

- Compromiso de llevar una política presupuestaria propia, no supeditada a las decisiones adoptadas en Madrid o Bruselas. No aceptar los límites del déficit público que establece el Gobierno de Madrid para las Comunidades Autónomas, puesto que ha de primarse la cobertura de las necesidades sociales.

- Cuestionar el pago de la deuda pública como prioridad. Impulsar y facilitar la elaboración de una auditoría de la deuda pública y comprometerse a no pagar la parte que se declare ilegítima. La auditoría de la deuda debe ser un proceso social, en el que el Gobierno colabore dando la información necesaria y pertinente a tal fin.

- Eliminar el diferencial de gasto público destinado a sanidad y educación respecto a la media europea hasta alcanzar el 7,2\% y el 5\% del PIB respectivamente.

- Diseñar con perspectiva de género todas las normas( incluidos los presupuestos) que emanan de la acción de gobierno.

\subsection{Sistema financiero}

- Defensa de un sistema financiero público vasco: dar marcha atrás en la conversión de las Cajas de ahorro en Banco, así como en Fundaciones Bancarias. Exigencia de que ni una sola acción de Kutxabank vaya al capital privado.

- Apertura de un debate social sobre el papel de las entidades financieras.

\subsection{Política de empleo y formación propia}

— Capacidad de decisión sobre las políticas. Las políticas de empleo se deben decidir aquí.

- Políticas activas y pasivas: Se requiere capacidad propia para llevar adelante todo lo que tiene que ver con políticas activas y pasivas de empleo (las prestaciones por desempleo).

- Potenciar los servicios públicos de empleo. La política de intermediación laboral debe realizarse mediante los Servicios Públicos de Empleo, abandonando el actual diseño de subvención y financiación de entidades privadas, que en muchas ocasiones no dan un servicio adecuado ni garantizan la igualdad de oportunidades.

- Cambio de orientación radical de los programas de las políticas de empleo.

- Se debe dotar a Lanbide de más medios humanos y estabilidad para poder dar una atención adecuada a las personas perceptoras de prestaciones 
económicas y desarrollar de manera personalizada las políticas de orientación e intermediación laboral.

- Formación para el empleo.

- Poner el modelo de formación para el empleo al servicio de las necesidades de la economía productiva y de los trabajadores y trabajadoras.

- Primar el papel de los centros de formación profesional e impedir que se asignen fondos de los planes formativos a sindicatos y patronal.

- Aumentar notablemente los medios destinados a perseguir el fraude en la contratación.

- Acabar con las licitaciones a la baja, que provocan la extensión de la precariedad laboral.

\subsection{Negociación colectiva y diálogo social}

— Compromiso de respetar las reglas democráticas básicas en la negociación colectiva: renuncia a impulsar los acuerdos en minoría.

— Dar cauces reales de participación sindical a la hora de fijar las políticas públicas.

- En el ámbito formal, y a todos los efectos, se debe respetar expresamente el grado de representatividad de cada organización sindical. Las decisiones se deben tomar por mayoría de cada parte.

- No funcionamiento de órganos en los que la mayoría de una parte no participe.

— Establecer un sistema de acreditación de la representación patronal.

\subsection{Política industrial}

\subsubsection{Preocupante situación de lal industria y de la politica industriales}

— La situación que vive la industria vasca es más que preocupante. En los últimos años son múltiples los casos de destrucción de empleo y de precarización de las condiciones de trabajo, en muchas ocasiones protagonizados por empresas multinacionales que presentan beneficios muy elevados como ARCELOR, ARKEMA QUIMICA, OUTOKUMPU, FORMICA, FAGOR ELECTRODOMESTICOS S.COOP, EATON, KIDER SA, DAEWOO en CAPV y Landaben en Nafarroa TRW, FAURECIA, KOXKA...

- La industria juega un papel fundamental en la economía vasca como en la sociedad (el 25\% de la población ocupada de Euskal Herria trabaja en el sector industrial), por lo que en ELA consideramos que se han de utilizar todos los instrumentos a nuestro alcance para desarrollar y generar una industria adecuada a las necesidades que tenemos como País. 
— Identificación de las cuestiones de mayor relevancia y prioridad que nos han llevado a la actual situación de alarma industrial:

1. La aplicación de políticas neo liberales.

2. Tenemos un modelo energético anticuado, insostenible que es dependiente de la especulación.

3. Entre las prioridades no aparecen en el lugar que se merecen las condiciones de vida y laborales, dando por buenas la precariedad y las reformas laborales y la estabilización de la negociación colectiva: se pone en el centro a las empresas en vez de a las personas.

4. Las políticas de formación para el empleo no son adecuadas.

5. Se apuesta por las grandes empresas y las transnacionales, sufriendo la peor cara de la globalización y destinándoles los principales esfuerzos y ayudas cuando la mayoría del empleo la crean las pymes autóctonas.

6. Se aplican las políticas y las medidas que estiman «convenientes» sin ninguna participación ni acuerdo en marcos de análisis y debate que no existen. Existe una total descoordinación entre Gobierno Vasco, Diputaciones Forales y ayuntamientos y menos aun con los Gobiernos del Estado y Europa.

7. Tenemos un nivel de $\mathrm{I}+\mathrm{D}+\mathrm{I}$ bajo, un $5 \%$ menor a la media de la UE y un $40 \%$ inferior al del Estado de la Unión Europea que mayor esfuerzo realiza en este vital ámbito para la sociedad y economía vasca.

8. Se está deslocalizando el tejido productivo industrial y el empleo que conlleva, sobre todo cuando depende de empresas transnacionales, con el único objetivo de aumentar los beneficios empresariales.

En conclusión es más necesaria que nunca la lucha, y colaboración para garantizar, desarrollar y transformar la industria de Euskal Herria. En ELA seguiremos trabajando para y luchando para que los gobiernos hagan lo que tienen que hacer : tomar medidas y políticas en beneficio de la sociedad.

\subsection{Medidas y políticas necesarias a implantar por el Gobierno Vasco y las Diputaciones Forales vascas}

1. Dejar a un lado el neoliberalismo y los recortes de todo tipo, fomentando el gasto público para mejorar e incrementar el tejido productivo vasco, cambiar la política fiscal por una más justa y efectiva para la sociedad.

Recuperar el control del empleo y las actividades estratégicas: accediendo a participaciones en empresas privadas y crear y fomentar empresas públicas, como un sistema financiero público de calidad al servicio de la sociedad. 
2. Impulsar e implantar un modelo de consumo y de energía verde y sostenible, conjugando y garantizando las necesidades actuales y de las futuras generaciones.

3. Apostar por el empleo digno y de calidad, creando un marco vasco de relaciones laborales y luchando con medidas e inspecciones contra la precariedad y al discriminación que sufren muchos colectivos sociales: las personas y la sociedad han de convertirse en el objetivo principal a potenciar.

4. Modificar completamente las políticas de formación para el empleo priorizando totalmente el papel de los centros de formación y los criterios objetivos y universales.

5. Apostar claramente por la pequeńa y mediana empresa, fomentando la transformación de la industria, condicionando las ayudas de todo tipo a condiciones laborales dignas y niveles de empleo adecuados.

Analizar y debatir un replanteamiento y recolocación de los procesos de producción y consumo, para garantizar las empresas, empleos, y productos locales. Evitar las dependencias externas será positivo para las pequeñas y medianas empresas, el empleo y el medio ambiente. Los certificados de procedencia y calidad pueden generar mayor valor añadido en la economía.

6. Obtener la participación, acuerdo e implicación de las personas y los agentes sociales en la toma de decisiones. Diseñar e implementar políticas coherentes e integrales para nuestro país, para que todas las instituciones públicas y Gobiernos trabajen en la misma dirección con el objeto de mejorar las condiciones de vida y laborales de las personas. Las instituciones vascas deben confrontar, de manera practica, con el modelo de la política industrial de la UE, que se basa en el criterio de que la mejor política industrial es la que no existe.

7. Convertir a la $\mathrm{I}+\mathrm{D}+\mathrm{I}$ en el principal impulsor de la economía, para generar mayor valor ańadido y transformar el modelo productivo. Es imprescindible situarnos a la cabeza de Europa en la inversión en este ámbito.

8. Defender y potenciar al máximo el tejido productivo y el empleo existente en la actualidad, poniendo freno a las decisiones de deslocalización y desmantelamiento industrial que estamos padeciendo en los últimos ańos desde al menos la gran crisis tal y como se ha expuesto en algunos de los ejemplos más significativos ocurridos desde el año 2008 hasta la actualidad en Euskal Herria.

La clase trabajadora vasca continuará luchando para garantizar y mejorar las condiciones de vida, pero los Gobiernos también deberán ser eficientes en su función, y si el Gobierno vasco abandona sus principales funciones la clase trabajadora vasca lo tendrá mucho más difícil para obtener nuestro fin último de obtener justicia y equidad en Euskal Herria. 


\subsection{Prestaciones sociales y establecimiento legal de derechos sociales}

— Renuncia expresa a adoptar cualquier medida que suponga un recorte de las prestaciones sociales.

- Dar marcha atrás de manera inmediata en los recortes aprobados en las prestaciones, que afectan a la cuantía de las mismas y han dejado a miles de personas sin derecho a la RGI, AES, etc... debido al endurecimiento de los requisitos de acceso.

- Establecimiento de las AES como derecho.

- Cobertura de todas las situaciones de dependencia, que serán atendidas por un servicio público y gratuito de calidad.

- Cobertura en la red pública de todas las plazas de educación que se demanden en la misma para el tramo 0 a 3 años.

- Acceso efectivo a una vivienda de alquiler social, y penalización fiscal importante a las viviendas vacías.

- Dignificar las prestaciones económicas relacionadas con la conciliación de la vida laboral, familiar y personal.

- Al igual que en política presupuestaria es necesario tomar decisiones unilaterales en políticas públicas, como por ejemplo en vivienda, fracking, etc... priorizando derechos económicos, sociales y medioambientales (si es el caso, no aceptando las resoluciones del Tribunal Constitucional).

\subsection{Carta de Derechos Sociales de Euskal Herria}

Las organizaciones sociales y sindicales que suscribimos la Carta de Derechos Sociales de Euskal Herria (entre ellas ELA), defendemos un modelo de sociedad que ponga en el centro el sostenimiento de la vida. Se realizan propuestas de medidas concretas que de implantarse supondrían un avance sustancial en esa dirección. La movilización es imprescindible para avanzar hacia los objetivos fijados en la propia Carta.

ELA entiende que la sociedad vasca necesita una alianza sindical y social fuerte, con espíritu crítico, con capacidad de propuesta y de consensuar prioridades. La Carta constituye un instrumento clave, que parte de la necesidad de cambiar radicalmente las políticas que se están aplicando en Euskal Herria y recoge nuestra propuesta de modelo alternativo de sociedad.

Los marcos normativos de la CAPV y de la Comunidad Foral de Navarra deben garantizar y promover que los derechos recogidos en la Carta se puedan ejercer en Hego Euskal Herria(HEH). La Carta de derechos sociales demanda la capacidad de decisión plena en materia económica y socio laboral y la construcción de nuestros propios instrumentos (normativos, institucionales, etc.). Realizar este proceso soberanista efectivo es parte de nuestro trabajo y nuestro empla- 
zamiento político. Este poder de decisión debe extenderse a todas las cuestiones importantes, de cualquier ámbito, que afecten a la población.

Junto a ello exigimos a las instituciones la aplicación inmediata de las medidas concretas recogidas en La Carta. Es necesario adoptar compromisos específicos y dotar de los recursos financieros necesarios para que estos compromisos se pueden cumplir.

Denunciamos que las políticas antisociales que se vienen aplicando están dando lugar a un empobrecimiento generalizado de la población. La distribución de la riqueza es cada vez más injusta. Aumentan el paro, la precariedad, la pobreza y las desigualdades económicas y sociales, porque no se hacen políticas públicas para dar la vuelta a la situación.

La élite política, en su mayoría aliada con el poder económico y financiero, elude sus responsabilidades en estas cuestiones esenciales. Su única preocupación es la de su imagen, que trata de lavar con propaganda y reparto de prebendas en mesas como la del mal llamado dialogo social.

No es suficiente rechazar lo que está pasando, hay que cambiar la situación de raíz y construir un modelo socio-productivo en Euskal Herria basado en la cobertura de las necesidades básicas, la redistribución de la riqueza, el empleo y los trabajos, la universalidad de los derechos, el liderazgo del sector público, la prioridad del interés colectivo respecto al impulso del individualismo, la eficiencia social y medioambiental de la política económica, la igualdad entre mujeres y hombres...

\subsubsection{Un cambio en las políticas presupuestarias, fiscales y sociales}

1. No aceptar las limitaciones presupuestarias y recortes que el Gobierno español ha aprobado. Revertir los recortes aprobados por las instituciones de Hego Euskal Herria.

2. Una política fiscal justa y progresiva que contribuya al reparto equitativo de la riqueza.

3. Desarrollar los servicios públicos propios para atender los sectores sociales estratégicos.

4. Aumentar las prestaciones sociales para responder al incremento del desempleo y de la pobreza.

5. Establecer por ley el reconocimiento de los siguientes derechos: situaciones de dependencia, educación pública, gratuita y de calidad para todas las distintas etapas educativas, protección económica de la infancia y juventud, acceso efectivo a una vivienda de alquiler social y penalización fiscal de las viviendas vacías.

6. Promover un sector público potente con capacidad de liderazgo para organizar nuestro modelo socio-productivo. 


\subsubsection{Una política de creación de empleo de calidad}

7. La creación de una política de empleo que defienda, cree y reparta empleo de calidad.

\subsubsection{Garantizar la participación de la sociedad}

8. Reestructurar todas las instituciones para posibilitar de manera efectiva la participación democrática de la sociedad en el diseño, toma de decisión y control de todas las políticas.

9. Auditoria de la deuda.

\subsubsection{Sostenibilidad de la vida y buen vivir}

10. Las personas, los pueblos y la naturaleza están por encima de los beneficios de las multinacionales:

- modelo socio-económico cuya prioridad sea el sostenimiento de la vida, al servicio de las personas y los pueblos.

- La solidaridad, la justicia e igualdad en las relaciones entre las personas y los pueblos.

- Por el derecho a decidir nuestro propio modelo económico, social y político para poder garantizar los derechos sociales, laborales, culturales y medioambientales.

- Rechazo de todas las instituciones al TTIP, CECA.

- Primar la producción de energías renovables y paralización y prohibición del fracking y su investigación, el transporte público colectivo y la intermodalidad, la reducción, reutilización, y reciclaje de residuos, la soberanía alimentaria...

\section{Conclusiones finales}

Querría destacar como las últimas conclusiones fundamentales de lo expuesto hasta el momento en este encuentro las siguientes:

1. La búsqueda de la máximización de la correlación de fuerzas de la parte social en estos procesos concluyendo sin ningún tipo de duda que los éxitos siempre son consecuencia directa de la lucha sindical y el papel secundario que el Gabinete y los servicios jurídicos jugamos en estos casos.

2. En los Grupos de empresas empresariales la valoración económica ha de realizarse a nivel de grupo en función de sus Cuentas consolidadas independientemente de que exista grupo laboral patológico o no. 
3. La prioridad absoluta del sindicato ELA además de su trabajo sindical propio es trabajar EL MODELO DE SOCIEDAD QUE PROPUGNA ELA realizando constantes propuestas en las políticas a implementar en la sociedad: fiscalidad, económica, política industrial... por los poderes públicos de los distintos ámbitos institucionales.

4. Destacar la solidaridad y la pertenencia de clase a la hora de plantear la lucha colectiva para conseguir los objetivos propuestos.

Para terminar una conclusión fundamental final que en ELA hacemos nuestra es:

«Luchando no sé si se conseguirán los objetivos propuestos pero tenemos la plena convicción de que sin luchar seguro que nunca se conseguirán ninguno de los objetivos propuestos.» 